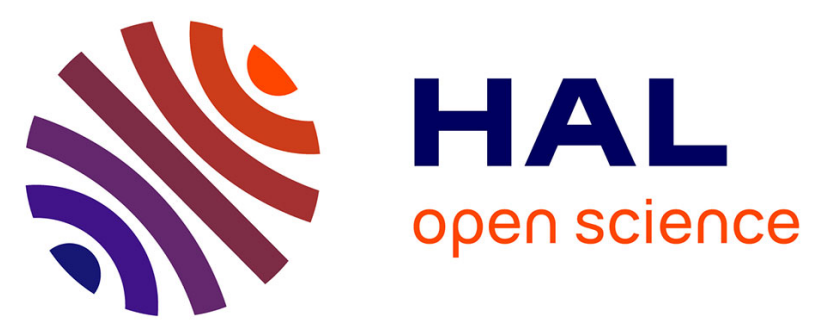

\title{
Assessing the precision of the iGrav superconducting gravimeter for hydrological models and karstic hydrological process identification
}

Benjamin Fores, Cedric Champollion, Nicolas Le Moigne, Roger Bayer, Jean Chery

\section{To cite this version:}

Benjamin Fores, Cedric Champollion, Nicolas Le Moigne, Roger Bayer, Jean Chery. Assessing the precision of the iGrav superconducting gravimeter for hydrological models and karstic hydrological process identification. Geophysical Journal International, 2017, 208 (1), pp.269-280. 10.1093/gji/ggw396 . hal-01526965

\section{HAL Id: hal-01526965 \\ https://hal.science/hal-01526965}

Submitted on 23 May 2017

HAL is a multi-disciplinary open access archive for the deposit and dissemination of scientific research documents, whether they are published or not. The documents may come from teaching and research institutions in France or abroad, or from public or private research centers.
L'archive ouverte pluridisciplinaire HAL, est destinée au dépôt et à la diffusion de documents scientifiques de niveau recherche, publiés ou non, émanant des établissements d'enseignement et de recherche français ou étrangers, des laboratoires publics ou privés. 


\title{
Assessing the precision of the iGrav superconducting gravimeter for hydrological models and karstic hydrological process identification
}

\author{
B. Fores, C. Champollion, N. Le Moigne, R. Bayer and J. Chéry \\ Géosciences Montpellier, CNRS, Université Montpellier, UA, F-34095 Montpellier,France.E-mail: benjamin.fores@gm.univ-montp2.fr
}

Accepted 2016 October 17. Received 2016 October 14; in original form 2015 December 15

\begin{abstract}
S UMMAR Y
In this paper we present the potential of a new compact superconducting gravimeter (GWR iGrav) designed for groundwater monitoring. At first, $3 \mathrm{yr}$ of continuous gravity data are evaluated and the performance of the instrument is investigated. With repeated absolute gravity measurements using a Micro-g Lacoste FG5, the calibration factor $\left(-894.8 \mathrm{~nm} \mathrm{~s}^{-2}\right.$ $\left.\mathrm{V}^{-1}\right)$ and the long-term drift of this instrument $\left(45 \mathrm{~nm} \mathrm{~s}^{-2} \mathrm{yr}^{-1}\right)$ are estimated for the first time with a high precision and found to be respectively constant and linear for this particular iGrav. The low noise level performance is found similar to those of previous superconducting gravimeters and leads to gravity residuals coherent with local hydrology. The iGrav is located in a fully instrumented hydrogeophysical observatory on the Durzon karstic basin (Larzac plateau, south of France). Rain gauges and a flux tower (evapo-transpiration measurements) are used to evaluate the groundwater mass balance at the local scale. Water mass balance demonstrates that the karst is only capacitive: all the rainwater is temporarily stored in the matrix and fast transfers to the spring through fractures are insignificant in this area. Moreover, the upper part of the karst around the observatory appears to be representative of slow transfer of the whole catchment. Indeed, slow transfer estimated on the site fully supports the low-flow discharge at the only spring which represents all groundwater outflows from the catchment. In the last part of the paper, reservoir models are used to characterize the water transfer and storage processes. Particular highlights are done on the advantages of continuous gravity data (compared to repeated campaigns) and on the importance of local accurate meteorological data to limit misinterpretation of the gravity observations. The results are complementary with previous studies at the basin scale and show a clear potential for continuous gravity time-series assimilation in hydrological simulations, even on heterogeneous karstic systems.
\end{abstract}

Key words: Time-series analysis; Time variable gravity; Hydrogeophysics; Instrumental noise; Hydrology.

\section{INTRODUCTION}

Groundwater in karst systems is an important resource of fresh water (Ford \& Williams 2013). In a context of Mediterranean climate where water resource is limited during a significant part of the year, karstic fresh water is vital. The knowledge of the characteristic of the karst and its functioning is fundamental for a long-term management of the water resource: to preserve and protect water quality, transfer and residence times of contaminants must be evaluated. The management of water quantity requires the identification and the quantification of the various karstic reservoirs. Indeed, karst aquifers are very heterogeneous with storage and transfer occurring both in matrix porosity, fractures and open voids. Moreover, spring discharge studies reveal specific nonlinear hydrodynamic behaviour. Classical hydrogeological methods using boreholes can provide measurements of hydrological properties but not comprehensive as they represent a very local area in a heterogeneous karstic medium. At the opposite, flux and chemical measurements from the spring can be interpreted only at the whole basin scale. Non-invasive and integrative hydrogeophysical methods such as gravity appear therefore relevant for spatio-temporal karst variability investigations at the field scale and bridge the gap between borehole and spring measurements. A detailed review of non-invasive geophysical methods applied to hydrogeological investigation in karst can be found in Chalikakis et al. (2011).

In the past several years, enhancement of the precision of gravimeters (both ground-based and space-borne) has allowed the monitoring of small gravity variations $\left(<100 \mathrm{~nm} \mathrm{~s}^{-2}\right)$ due to hydrogeological processes. At the local scale (less than $10 \mathrm{~km}$ ), gravity experiments have been conducted in a large variety of contexts showing the sensibility of gravity measurements to water storage changes (WSCs; Hasan et al. 2008; Jacob et al. 2009; Longuevergne et al. 2009; Pfeffer et al. 2013). These previous studies monitored successfully spatial and/or temporal variations of gravity due to 
hydrological processes, leading to a detailed understanding of the hydrological systems. Assimilated in hydrological models, gravity measurements can also lead to a better constraint of the inversion procedure (Creutzfeldt et al. 2010a; Hector et al. 2013; Piccolroaz et al. 2015). The major advantage of gravity signal for hydrological studies is the direct relation between gravity variations and water masses. Compared to other geophysical methods, only the Magnetic Resonance Sounding (MRS) is also a direct measurement of groundwater. One of the main asset and drawback of the gravity method is its fundamental integrative property. Thus, even if a vertically resolved profile of water content cannot be retrieved from gravity measurements alone, it remains a geophysical non-invasive method well suited for hydrological studies. The large horizontal investigation scale of the gravity method and MRS (between a few and a hundred meters) is therefore relevant for groundwater studies in heterogeneous hydrosystems such as karsts.

Superconducting gravimeters (SGs) are stationary and have high power requirements but are the most precise gravimeters. With these instruments, one can look in detail at the relation between gravity variations and WSCs taking into account site effects (Deville et al. 2013) or spatial heterogeneities. This study investigates the potential of a modern SG: GWR iGrav (Warburton et al. 2010) for karst groundwater resource monitoring. Three main issues are discussed: (i) are the precision and the long-term stability of a modern SG appropriate for WSC monitoring? (ii) what is the added value of continuous SG gravity measurements compared to an AG dataset? (iii) which kind of hydrogeological processes can be monitored from gravity measurements by modelling? A 3 yr gravity and meteorological dataset from the GEK ('Géodesie en Environnement Karstique': Geodesy in Karstic Environment) observatory in the Larzac plateau (South of France) is used for that purpose. The observatory and the investigated area are presented in the first part. Then the gravity data processing and precision is evaluated. The groundwater impact on the gravity signal is discussed in synergy with complementary data (evapotranspiration and precipitation) and finally interpreted with a tank modelling approach.

\section{INVESTIGATED AREA}

\subsection{Hydrogeological and environmental settings}

Gravity measurements were collected in the southern part of the Larzac plateau, in the south of France (Fig. 1). The mean altitude of the plateau is about $700 \mathrm{~m}$ above sea level without steep topography. The altitude, the Atlantic Ocean and the Mediterranean Sea have an impact on the climate. The rainfall is mainly influenced by the Atlantic Ocean even if large precipitation system from the Mediterranean area sometimes reaches the southern part of the plateau. The annual mean precipitation is around $1000 \mathrm{~mm}$, mostly in autumn and winter. Snowfalls are rare and not persistent. The Landscape is a mix of croplands, grassland and pine forest. Except for an N-S highway, urbanization is scarce and agriculture is the main economic activity.

A detailed description of the geological setting can be found in Bruxelles (2001). The Larzac plateau is a regional nearly horizontal formation of Jurassic dolomite (and to lesser extend limestone) with a thickness of about $200 \mathrm{~m}$. Major E-W faults cut the plateau in independent hydrogeological units. The investigated area is a catchment with only one spring (the Durzon spring, $533 \mathrm{~m}$ a. s. 1.), discharging a mean outflow of $\sim 1.6 \mathrm{~m}^{3} \mathrm{~s}^{-1}$. There are no other minor springs or pumping wells and precipitation is the only source of recharge. The estimation of the Durzon basin surface is about $110 \mathrm{~km}^{2}$ (Ricard \& Bakalowicz 1996).
Surface observations show fractures mainly oriented in the NS direction. Alteration of dolomite and ghost rock weathering (Dubois et al. 2014) produce dolomite sand without clay cover. Dolomite sand is observed at the surface and in caves and tends to clog fractures and voids. Known caves are mainly vertical shafts to a maximum depth of about $120 \mathrm{~m}$. The unsaturated zone is therefore deeper than $100 \mathrm{~m}$ in the Durzon catchment. No runoff is observed even during intense rainfalls and temporary lakes can appear in the southern part of the catchment (Bruxelles 2001). Previous gravity studies (Jacob et al. 2009; Deville et al. 2011) indicate large water storage at the seasonal scale in the epikarst (the upper altered zone of the karst), up to 50 per cent of the annual precipitation amount. However these authors are limited in their hydrologic interpretation because of the less precise absolute or spring-based relative gravimeter used. Chemical studies of the low-flow spring water also reveal long residence time in the unsaturated zone (De Montety, Personal communication). On the Durzon catchment, most of the rainwater is then expected to be stored in the epikarst and infiltrates slowly through the dolomite to the active karst network called hereafter 'slow transfer'. However, as the Durzon spring shows immediate flood peaks after intense rains, fast transfer should occur in some areas of the catchment. The quantification of the fast and slow transfer at the local scale is not achievable in previous studies as no continuous and precise enough gravity dataset are available.

\subsection{The GEK observatory and the instrumental setup}

The GEK (Geodesy in Karstic Environment) observatory is a geophysical and geodetic observatory of OREME (Observatoire de REcherche Méditerranéen de l'Environnement, http://www.oreme.org/) dedicated to hydrogeophysical experiments. It is also a part of the network of hydrogeological experimental sites ' $\mathrm{H}+$ '.. One of the objectives of the observatory is to provide up-to-date geodetic and geophysical measurements to constrain hydrogeological models. Its location in the northwestern part of the basin (Fig. 1) is based on preceding studies indicating relatively high groundwater storage (Jacob et al. 2010). The observatory landscape is grassland located $1000 \mathrm{~m}$ away from a national highway. The soil is thin without clay, and dolomite rock and dolomite sand are seen at the surface. A cave with an underground small river has been mapped at $100 \mathrm{~m}$ depth below the building.

The GEK observatory is a small wood building $\left(56 \mathrm{~m}^{2}\right)$ with stabilized temperature $\left(20^{\circ} \mathrm{C}\right)$ and concrete pillars linked to bedrock to ensure low seismic noise measurements. The instrumental setup (Fig. 2) is composed of a large selection of continuous instruments: a GPS for ground deformation monitoring, a large band seismometer, a superconducting iGrav gravimeter, an electrical resistivity tomography system, two rain gauges, and a flux tower for eddy correlation. Three boreholes also exist on the site up to $50 \mathrm{~m}$ depth (core drilled). In the present study, only the gravimeter, the rain gauges and the flux tower are used (Fig. 2). The precise topography around the observatory (about 300 meters radius) was obtained with a kinematic GPS and completed by the IGN $25 \mathrm{~m} \times 25 \mathrm{~m}$ resolution digital elevation models for the rest of the basin. More details and data are available online: http://data.oreme.org/gek/home.

\subsubsection{Meteorological measurements}

Rainfall has been monitored starting in 2012 at the site with two tipping buckets pluviometers for redundancy. Rainfall amounts were assumed locally homogeneous from comparison between our two 

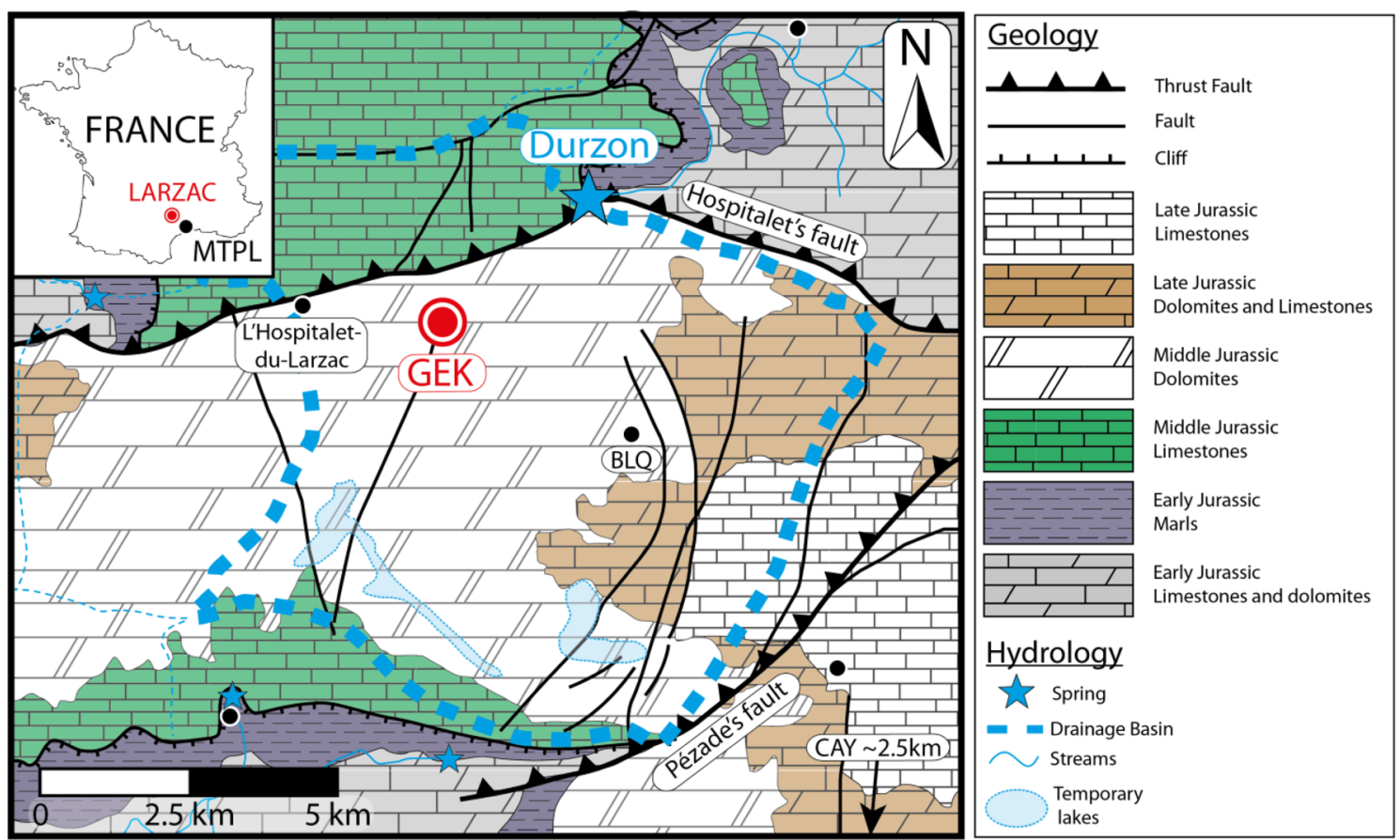

Figure 1. Location map and hydrogeological settings. The red dot shows the GEK observatory position. BLQ and CAYL are rain gauge stations. Modified after Jacob et al. (2009).
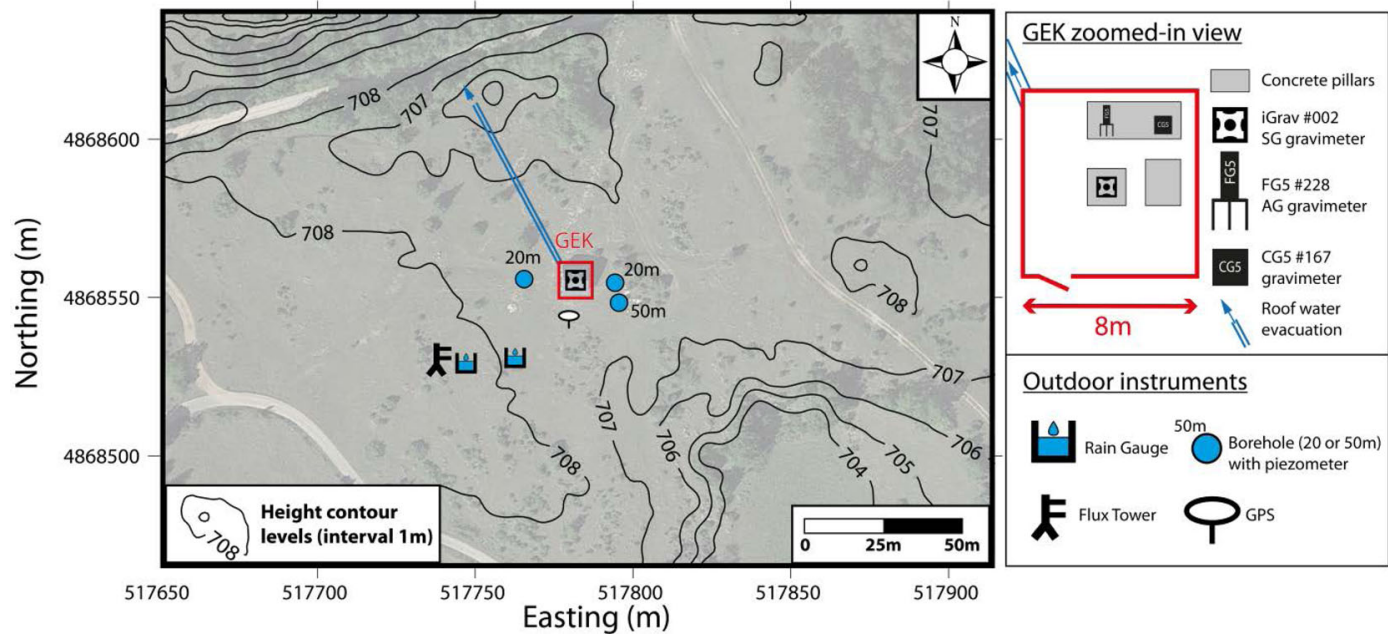

Outdoor instruments

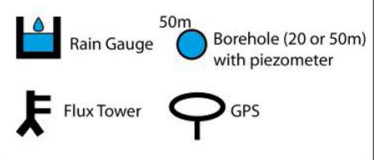

Figure 2. Detailed map of the surrounding of the GEK observatory. The topography is almost flat in the first tens of meter around the building and very smooth further.

pluviometers on the site. Between 2006 and 2011 a rain gauge in La Blaquererie (BLQ), $4 \mathrm{~km}$ southeast to the observatory was used. Before 2006, rainfall was taken from the Météo-France CAYL station, $12 \mathrm{~km}$ away (S-SE). Evapotranspiration has been monitored since 2013 by an eddy covariance flux tower. The system is composed of one sonic anemometer (Campbell CSAT3), a gas $\mathrm{H}_{2} \mathrm{O}$ and $\mathrm{CO}_{2}$ analyser (Licor LI-7500A) and a meteorological station (pressure, humidity, temperature). Actual evapotranspiration (AET) was computed from these measurements using the EddyPro 5.2.1 software (www.licor.com/eddypro) and the time-series was gap filled (gaps mainly caused by unfavourable meteorological conditions) with the web tool of the Max Planck Institute for Biogeochemistry (http://www.bgc-jena.mpg.de/ MDIwork/eddyproc/).

Before the flux tower installation, potential evapotranspiration (PET) was computed using the Pennman-Monteith's formula
(Penman 1948) by the national meteorological agency MétéoFrance at CAYL station. In previous studies the actual evapotranspiration was estimated from PET by applying a constant coefficient found to respect a multi-year global mass balance (Jacob et al. 2008). However, it could lead to substantial underestimation of evaporation during winters and strong overestimation during summers (up to $70 \mathrm{~mm}$ ) because of water unavailability in the soil. Therefore, before 2013 a seasonal coefficient found by the comparison of PET and flux tower AET data from 2013 to 2015 was used.

\subsubsection{Gravity measurements}

The GWR iGrav gravimeter is a new generation SG (Warburton et al. 2010). In our case, iGrav \#002 was the first deployed iGrav. An SG is a relative gravimeter physically based on the magnetic 
Table 1. Calibration between SG $1 \mathrm{~Hz}$ raw voltage and AG sets (100 drops/set, drop interval: $10 \mathrm{~s}$, set interval: $1 \mathrm{hr}$ ) with the standard deviation of the fit residuals. Very noisy periods (earthquakes) are removed before the calibration (up to a few hours).

\begin{tabular}{lcccc}
\hline Day start time & $\begin{array}{c}\text { Duration } \\
(\mathrm{d})\end{array}$ & $\begin{array}{c}\text { Number of } \\
\text { sets }\end{array}$ & $\begin{array}{c}\text { Calibration factor } \\
\left(\mathrm{nm} \mathrm{s}^{-2} \mathrm{~V}^{-1}\right)\end{array}$ & $\begin{array}{c}\text { Standard deviation } \\
\left(\mathrm{nm} \mathrm{s}^{-2}\right)\end{array}$ \\
\hline 2011-07-04 10:50 & 6.0 & 144 & $-894.17 \pm 0.96$ & 8.60 \\
2011-08-25 10:15 & 6.4 & 153 & $-895.49 \pm 0.79$ & 6.97 \\
2011-12-06 15:30 & 6.3 & 150 & $-895.54 \pm 0.86$ & 15.80 \\
2012-02-20 15:15 & 6.0 & 144 & $-895.94 \pm 1.03$ & 7.17 \\
2013-03-25 14:35 & 2.1 & 50 & $-894.65 \pm 1.21$ & 5.24 \\
2013-06-13 11:45 & 5.0 & 120 & $-895.38 \pm 0.97$ & 7.30 \\
2014-07-25 09:15 & 4.0 & 96 & $-893.63 \pm 0.86$ & 6.68 \\
2014-12-02 10:35 & 3.0 & 72 & $-893.74 \pm 1.31$ & 14.60 \\
\hline
\end{tabular}

levitation of a sphere (Hinderer et al. 2007). The use of very stable superconducting current allows enhanced precision and long-term stability. The drift estimation and the calibration of the SG were performed by comparison with an absolute gravimeter. More details on the drift and the precision of the SG are presented in the processing part of this paper as for such a new instrument, they are critical for data interpretation. One can note that no estimation of the long-term drift ( $>1 \mathrm{yr}$ ) is available in previous studies. The absolute gravimeter used in the observatory was Micro-g Lacoste FG5 \#228 belonging to national gravity CNRS-INSU facility (https://gmob.resif.fr). Compared to previous-generation SGs, the iGrav has a reduced size and easier installation (two customers themselves, $3 \mathrm{~d}$ ). Starting at room temperature with a He-free iGrav, gravity data were obtained less than 3 weeks after the setup (Le Moigne et al. 2011) which is short compared to previous SG and makes it potentially adapted to short term and/or field experiments (Kennedy et al. 2014).

\section{SG DATA PROCESSING AND PERFORMANCE}

Raw SG data is the $1 \mathrm{~Hz}$ output voltage needed to keep the sphere at the same position between both coils. SG data processing involves the calibration to convert the output voltage to acceleration, signal processing (classical steps: decimation - steps and gap filling - despiking) and drift correction. Then, the correction of all the non-local hydrological signals (earth and ocean tides, atmospheric pressure impact, non-local hydrology and polar motion) can be achieved to get the acceleration residuals linked to local hydrology. Such a classical processing is briefly presented below and more details can be found in the literature (e.g. Hinderer et al. 1991; Hector et al. 2014).

\subsection{Drift, calibration and pre-processing}

\subsubsection{Pre-processing}

SG 1-Hz raw data were first decimated, filtered and gap filled (e.g. Hinderer et al. 2007). The most frequent reason of a step in the time-series was power failure induced by lightning storms. The distinction between steps and water loading signals can be difficult and corrections are always subjective. For the 3 yr of measurements, 2 major and 10 minor offsets are corrected for a total of $4000 \mathrm{~nm} \mathrm{~s}^{-2}$. This is a potential major source of errors and could add some additional drift if the correction is biased. Consequently, protection against power surges and outages must be carefully implemented.

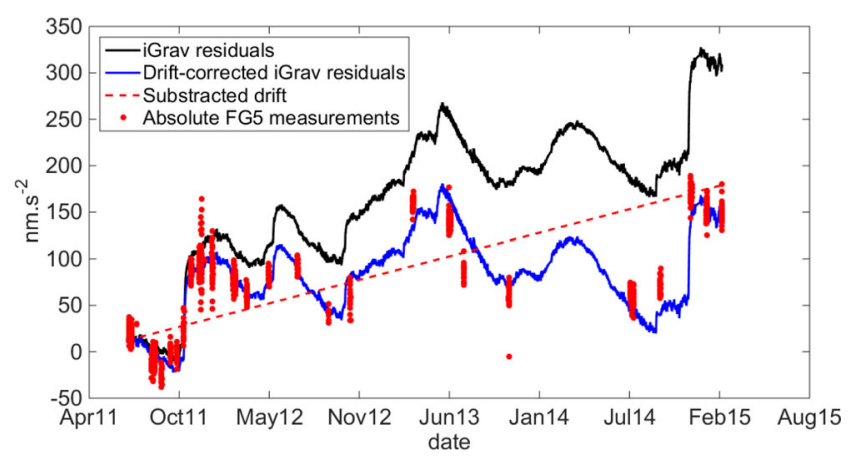

Figure 3. Gravity residuals before (black line) and after drift corrections (blue line). Reference absolute gravity measurements are in red. The drift is $45 \mathrm{~nm} \mathrm{~s}^{-2} \mathrm{yr}^{-1}$ (red dotted line) with a standard deviation of $18 \mathrm{~nm} \mathrm{~s}^{-2}$.

\subsubsection{Calibration}

The calibration from voltage to acceleration was done using an absolute gravity reference. Voltage change is inversely proportional to the vertical acceleration change (e.g. Francis 1997; Hinderer et al. 1998). In this study a free-fall gravimeter (FG5) was used, measuring average absolute gravity over several tens of drops with a formal error $\sim 10-20 \mathrm{~nm} \mathrm{~s}^{-2}$ (Niebauer et al. 1995). When possible, FG5 measurements were performed over periods longer than $5 \mathrm{~d}$ which is optimal to calibrate accurately a SG (Francis et al. 1998). Eight experiments allowed us to determine the calibration factor at the 0.1 per cent level (Table 1). The coefficient is constant as all the calibration factor estimations are consistent (error bars are overlapping) except for the summer 2014. The total amplitude of the $\mathrm{DC}$ signal was about $3 \mathrm{~V}$. However, the amplitude of the hydrological signal was much smaller and did not exceed $0.2 \mathrm{~V}$. Consequently, a 0.1 per cent error on the calibration factor will lead to maximum $3 \mathrm{~nm} \mathrm{~s}^{-2}$ error (the effect of $7 \mathrm{~mm}$ of water) in the gravity signal. The weighted mean of the 8 calibrations was used for the whole time-series: $-894.8 \mathrm{~nm} \mathrm{~s}^{-2} \mathrm{~V}^{-1}$.

\subsubsection{Instrumental drift correction}

As with all relative gravimeters, SGs drift over time. The amplitude and the linearity of the drift are major concerns for hydrogeological studies (and other long-term gravity applications). Yet no estimation of an iGrav long-term drift ( $>1 \mathrm{yr}$ ) is available. Smaller than for spring-based gravimeters, SG drift can be constrained by regular absolute measurements. More than 20 absolute FG5 measurements over $3 \mathrm{yr}$ (Fig. 3) allowed us to evaluate the linear iGrav \#002 drift at $45 \mathrm{~nm} \mathrm{~s}^{-2} \mathrm{yr}^{-1}$ (equivalent to a loss of about $100 \mathrm{~mm}$ of water per year). A higher polynomial order drift did not better fit our 
data, as expected for only few years of measurements (Van Camp \& Francis 2007). As the drift appears to be stable, only one or two measurements per year with an absolute gravimeter are therefore needed.

\subsection{Non-local hydrological gravity corrections}

\subsubsection{Non-local loading corrections}

Distant loading including the contribution of oceans, the atmosphere and non-local hydrology were corrected. Global loading effects were granted by the Institut de Physique du Globe de Strasbourg (IPGS) loading service (http://loading.u-strasbg.fr/GGP/index.html) and calculated using global land-ocean-atmosphere models. Only the 'non-local' parts of these models were removed from gravity signal. The 'non-local' part is defined for a radius larger than $0.25^{\circ}$ $(\sim 20 \mathrm{~km})$ from the site and represents about 15 per cent of the local signal. Over the three studied years, the non-local differences between different hydrological models were usually less than $1 \mathrm{~nm} \mathrm{~s}^{-2}$ and always smaller than $5 \mathrm{~nm} \mathrm{~s}^{-2}$ (12 mm of water). The GLDAS model for hydrology and the MOG2D model for ocean and atmosphere were used, which are detailed in the Supporting Information.

\subsubsection{Tides and local pressure correction}

Gravity tide effects were the largest gravity variations (about 90 per cent of the signal). The frequency-dependent phenomena (solid earth tides, ocean tides) were computed using the ETERNA 3.4 software (Wenzel 1996) with the KSM03 tidal potentials (Kudryavtsev 2004). The polar motion contribution was calculated from the International Earth Rotation Center data (http://www.iers.org). Local atmospheric pressure effect (within $0.25^{\circ}$ ) was removed using a linear admittance of $-2.82 \mathrm{~nm} \mathrm{~s}^{-2}$ $\mathrm{hPa}^{-1}$ found by linear regression. Frequency dependent admittances have been tested without any improvement.

\section{3 iGrav performance and noise level}

To investigate the noise level, power spectral density (PSD), seismic noise magnitude (SNM; Banka 1997) and Allan deviation (Allan 1987) of the gravity residuals were calculated. PSD reveals that the iGrav \#002 experiences a noise level of $1 \mathrm{~nm} \mathrm{~s}^{-2} \mathrm{~Hz}^{-0.5}$ during quiet days (no swell, no earthquake) as expected from the specification of the manufacturer (Warburton et al. 2010). SNM demonstrates the low-noise environment of the GEK among others GGP (Global Geodynamic Project, Hinderer \& Crossley 2004) stations. PSD and SNM processing are presented and discussed further in the Supporting Information.

We use the Allan deviation to investigate the stability of the iGrav (Fig. 4). During the first few seconds of integration, stability is relatively low (Allan deviation is high) due to high frequency seismic noise. Then stability increases up to $1 \mathrm{~nm} \mathrm{~s}^{-2}$ after $\sim 10$ $60 \mathrm{~s}$ of averaging times for data including the tidal signals (Fig. 4, blue line). For a longer averaging time, the stability of the nontide-corrected signal decreases again due to the tides effects, up to $\sim 100 \mathrm{~nm} \mathrm{~s}^{-2}$ for $6 \mathrm{hr}$, which is half the period of the semi-diurnal tides. When tides and atmospheric loading are removed (Fig. 4, red line) the stability continues to increase, and reaches a maximum of $0.1 \mathrm{~nm} \mathrm{~s}^{-2}$ after $10^{3}$ seconds of integration. For hydrological applications, a noise level of $1 \mathrm{~nm} \mathrm{~s}^{-2}$ ( $2.4 \mathrm{~mm}$ of water) is generally

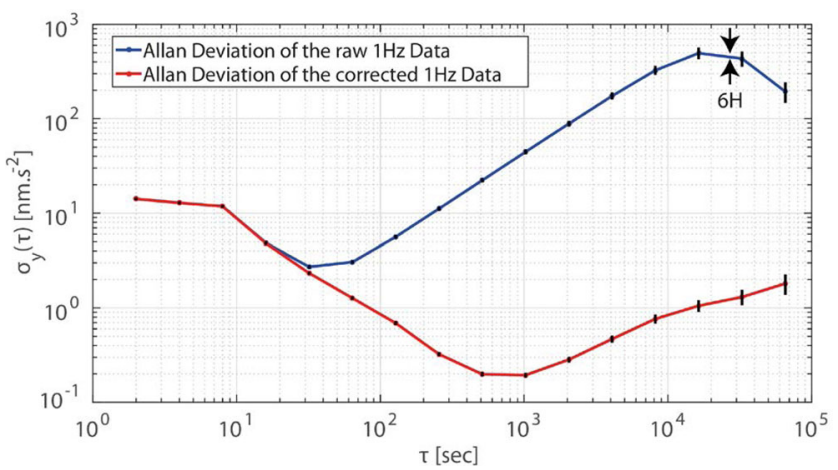

Figure 4. Allan deviation of the $1 \mathrm{~Hz}$ iGrav data for the two first weeks of August 2014. Allan deviation of the raw data is plotted in red and Allan deviation on igrav data corrected from tides, in blue.

sufficient and reached by the integration time of $60 \mathrm{~s}$ used in the standard SG processing.

Finally, the size reduction and the simplification of the iGrav do not increase noise levels (PSD and SNM similar to other SG), precision and stability relative to older SGs. From the site and the observatory point of view, the low seismic noise level allows studies of small hydrogeological induced gravity variations (less than $1 \mathrm{~nm} \mathrm{~s}^{-2}$ or few mm of water) at various time scales. The final accuracy of hydrological gravity residuals do not depend on iGrav high performances but rather on corrections applied (nonlocal hydrological signals and offsets).

\section{HYDROLOGICAL RESIDUALS IN TERPRETATION}

After data processing and corrections, the gravity residuals (Fig. 5) are correlated to WSCs: gravity increases after rainy months (autumn and winter) and decreases during the dry season (spring and summer). The equivalent water height change (right axis, Fig. 5a) is commonly defined as the thickness variation of a horizontal infinite water slab which produces the same gravity variation (Bouguer plate, eq. 1):

$d h=\frac{d g}{2 \pi \rho_{\mathrm{w}} \mathrm{G}}$

With $d g$ the gravity variation (in $\mathrm{m} \mathrm{s}^{-2}$ ), $d h$ the equivalent water slab thickness $(\mathrm{m}), \rho_{\mathrm{w}}$ the density of water $\left(1000 \mathrm{~kg} \mathrm{~m}^{-3}\right)$ and $G$ the universal gravitational constant.

Typical precipitation does not exceed $50 \mathrm{~mm}$ in a single event but two large precipitation events exceeding $200 \mathrm{~mm}$ were measured in October 2011 and in November 2014. Consequences of these intense rainfalls are seen on both gravity data and spring discharge (Fig. 5) as a sharp increase and no enhanced gravity decrease afterwards. Usually with an average low flow around 1.2 $\mathrm{m}^{3} \mathrm{~s}^{-1}$, the spring discharge can reach then more than $10 \mathrm{~m}^{3} \mathrm{~s}^{-1}$. The amplitude of gravity variations $\left(\sim 150 \mathrm{~nm} \mathrm{~s}^{-2}\right.$ equivalents to $\sim 360 \mathrm{~mm}$ of water) has the same order of magnitude as previous gravity studies in the surrounding area (Jacob et al. 2010; Deville et al. 2013). Evapotranspiration is almost insignificant in autumn and winter. Most evapotranspiration (a few millimetres per days) occurs during spring and summer when right soil water content and meteorological conditions are met. 

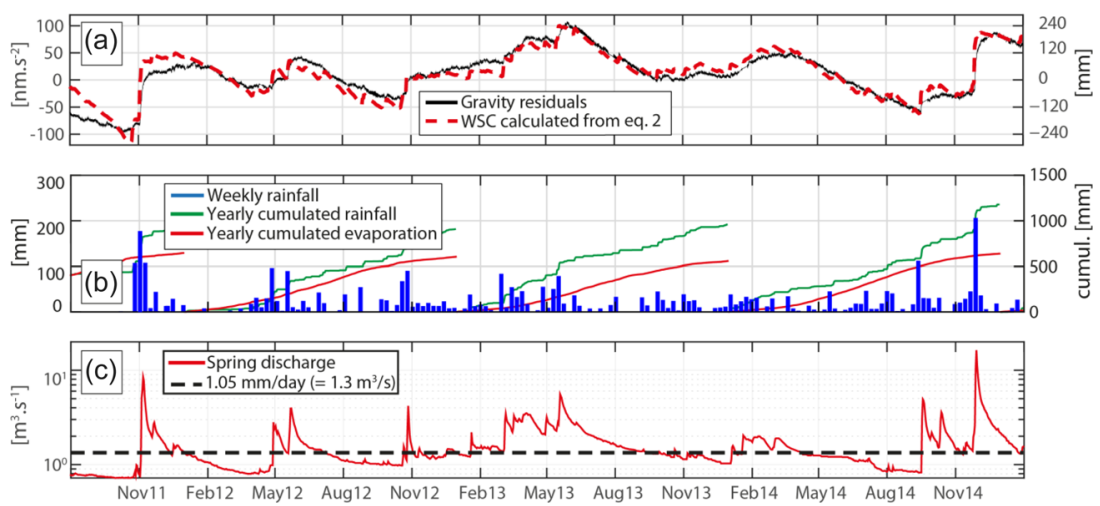

Figure 5. Gravity, meteorological and hydrological observations on the Durzon catchment since May 2011. (a) iGrav gravity residuals (black line) and gravity effect of a water balance (red dotted line) from rains, evaporation and constant discharge of $1.05 \mathrm{~mm} \mathrm{~d}^{-1}$ (see the text). The right axis gives the equivalent water height according to eq. (1). (b) Daily rainfall (blue bars). Yearly cumulative rainfall (green line) and evapotranspiration (red line) are also represented. (c) Durzon spring discharge (logarithmic $y$-axis, red line). The black dotted line represents the constant discharge applied on the mass balance in the top figure, scaled to the whole basin.

\subsection{Local mass balance with a constant discharge}

As the gravity is sensitive to the local WSC, daily water balances (eq. 2) were done at the observatory scale:

$\mathrm{WSC}=R-\mathrm{AET}-Q$,

where WSC is the water storage change, $R$ the rainfall, AET the actual evapo-transpiration and $Q$ the local discharge. Rainfall and actual evapotranspiration were known from surface measurements and WSC was converted from gravity using eq. (1). The remaining unknown, the discharge, was therefore adjusted to fit the gravity residuals.

Because WSC is only representative of the area investigated by the gravimeter, the local discharge is not equivalent to the spring discharge. We interpret this local discharge as water leaving the porous epikarst in depth through the fractures of the underlying healthier medium (Jacob et al. 2008). However, the epikarst thickness is unknown and it is therefore not possible to precisely determine the radius investigated by the gravimeter. We expect it to be hundreds of meters maximum as the epikarst is less than $100 \mathrm{~m}$ thick (McCulloh 1965). A constant loss of $\sim 1 \mathrm{~mm} \mathrm{~d}^{-1}$ fits remarkably the gravity residuals (RMS of $17 \mathrm{~nm} \mathrm{~s}^{-2}$ equivalent to $40 \mathrm{~mm}$ of water, Fig. 5a). Even after moderate or high rainfall, the constant discharge fits the observed gravity. One can also convert the local discharge $(Q)$ in spring discharge by using the area of the whole Durzon basin $\left(110 \mathrm{~km}^{2}\right)$. Thereby, a value of $1.3 \mathrm{~m}^{3} \mathrm{~s}^{-1}$ is found which is coherent with the average low flow spring discharge (Fig. 5c).

The first analysis of the SG residuals and the water balance evidence also the impact of the accuracy and localness of meteorological measurements. The fit between the local mass balance and SG residuals (Fig. 5a) is better after October 2012 (the RMS is halved, from 23 to $12 \mathrm{~nm} \mathrm{~s}^{-2}$ ), when the update of the meteorological data is done (local rain gauges and flux tower AET). From previous studies in the same area, the rainfall is known to be quite homogenous at the basin scale on a yearly basis (Jacob et al. 2009). However, some events have shown significant difference between the new rain gauges and those used previously few kilometres away. Those differences may be compensated at the seasonal cycle scale but the rain spatial heterogeneity is critical for a local study with a high frequency gravity sampling. Concerning evapotranspiration, the use of scaled PET is consistent with the water mass balance at the seasonal cycle scale only. During the end of summer, scaled PET overestimates the actual evapotranspiration: the absence of water in the first meters of the ground limits the evaporation. For studies or experiments working at the event scale or with continuous measurements, accurate and local measurements of meteorological parameters are critical. In the present study, without accurate evapo-transpiration, one could misinterpret the differences between mass balance and gravity measurements as heterogeneities of the karst, fast transfer or nonlinear processes.

\section{2 'Site effect' and short-term gravity response}

The previous mass balance provides information on the mean longterm discharge. For an interpretation of the gravity residuals at the level of the SG precision, site effects (caused by the building and the surrounding topography) on the gravity should be estimated. Recent studies have shown that it can be significant (Creutzfeldt et al. 2010b; Hector et al. 2014). For the GEK observatory, the methodology described in Deville et al. (2013) is used to compute these effects. Both topography and building mask effects are depth dependent, as the footprint of the gravimeter increases with the distance.

The gravity effect of an infinite horizontal layer of water gives the well-known theoretical admittance of $0.42 \mathrm{~nm} \mathrm{~s}^{-2}$ per mm of water (eq. 1). In experimental studies, the topography is never flat and water is distributed over it, leading to a non-horizontal slab. As expected, the quasi-flat site around our observatory (Fig. 2) returns a small topographic effect: it reduces the effect of a Bouguer slab by less than 3 per cent (Fig. 6).

Beside the topographic effect, the building acts as a mask for the rainfall: indeed, the gravimeter is most sensitive to the region directly underneath the building where no water falls. To avoid local concentration (difficult to model), all the water falling on the roof is routed away (100 m, Fig. 2) by an underground pipe. The mask effect evaluation is especially needed for high precision and continuous measurements, given that there are measurements during and just after the rainfall. The mask effect is significant for all the possible gravimeters of the observatory (Fig. 6), reducing by 80 per cent the instantaneous effect of rainfall events on the SG data. For the FG5 absolute gravimeter, the mask impact is smaller (40 per cent). The iGrav concrete pillar is indeed located in the centre of the building (Fig. 2) and its sensor is closer to the floor $(0.35 \mathrm{~m}$ above the floor for the iGrav against $1.20 \mathrm{~m}$ for the FG5). Both characteristics tend to increase the mask effect on the iGrav. For completeness and future 


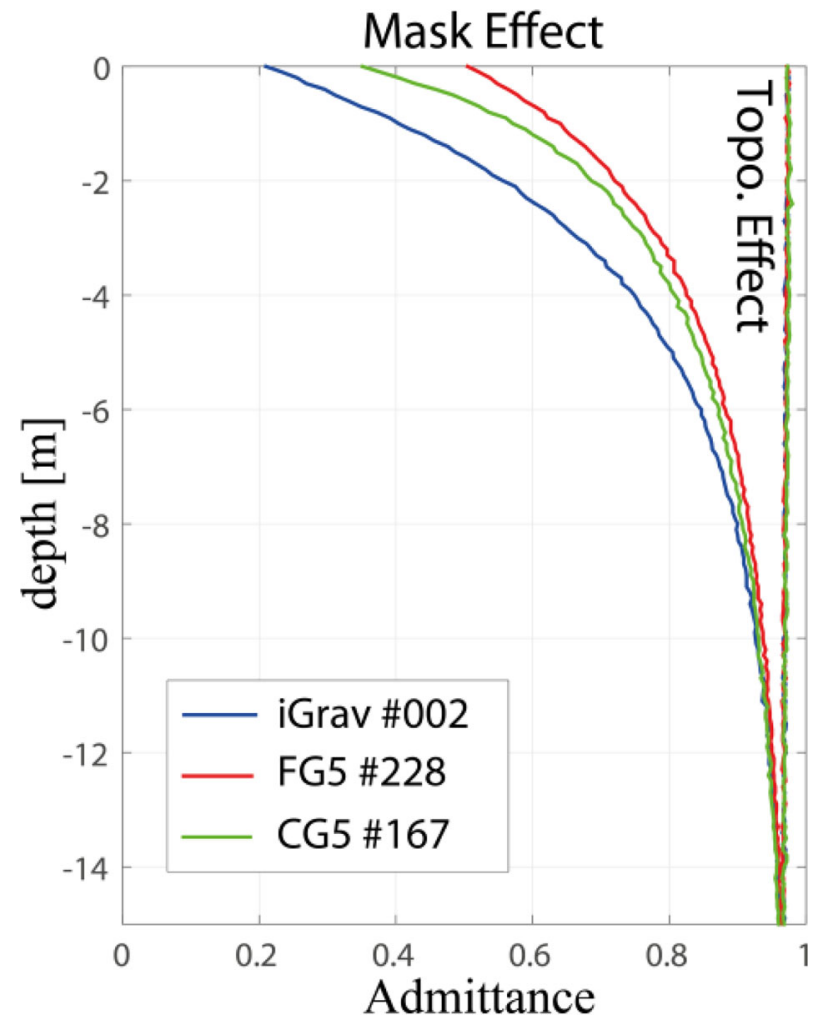

Figure 6. Theoretical effects of the building and topography on the gravity induced by a water layer at different depths. The effect is computed at the FG5 (red), the CG5 (green), and iGrav (blue) sensors position. The admittance of the building mask effect is the ratio between a truncated layer and an infinite layer attraction. The admittance of the topographic effect is the ratio between a layer following the topography and a flat layer. The full site effect is the sum of both effects.

studies, the effect on a spring-based relative CG5 gravimeter (same pillar than the FG5, sensor closer to the floor) is also estimated and stands between FG5 and iGrav (Fig. 6).

On the SG signal, the mask effect can be experimentally evaluated after the rainfalls through the ratio between expected gravity variations (eq. 1) and the observed gravity variations. Hours after rain events, the gravity increases are always smaller than the full slab effects (Table 2). During the (dry) following days, the gravity still slowly increases, with the water infiltrating deeper (Table 2, 'Admittance 10 after'). The admittance between gravity and rainfall is not linear and depends on the soil moisture. In a dry soil (for example October 2011 and September 2014 events), water from the rainfall is stored at shallow depth where the mask effect is important (and the gravity effect reduced). In moist soil conditions (November 2011 and 2014) the gravity increases until the expected full Bouguer effect of the rain. One can note that the Durzon spring flood peaks (due to fast transfer coming from other parts of the basin) are also sensitive to the pre-event soil moisture: the flood peak for a same amount of rain $(100 \mathrm{~mm})$ is different for the end of October 2011 and May 2012 (respectively 9 and $4 \mathrm{~m}^{3} \mathrm{~s}^{-1}$, Fig. 5a). One can note that the mask effect is not necessarily only a drawback. As it depends on the depth, the time to recover the expected gravity value after a rainfall can be used to estimate a vertical groundwater flux.

In summary from gravity variations and local water mass balance, two main points can be addressed: (1) The observatory area is not representative of the basin fast groundwater transfer (around 15 per cent of the discharge after strong events floods, Pinault et al.
2001). Indeed, when soil moisture is already high, incoming water does not remain in the masked first meters and observed gravity measurements reach an infinite slab effect (minus AET and a slow constant discharge, Fig. 5, Table 2). Then no rainwater bypasses the matrix storage: all is stored in subsurface and slowly discharged. (2) The water mass balance performed at the local gravimeter scale may be representative of the slow transfer at the scale of the whole basin. Indeed, the $1 \mathrm{~mm} \mathrm{~d}^{-1}$ of depth transfer from the local mass balance scaled by the surface of the Durzon basin $\left(110 \mathrm{~km}^{2}\right)$ is equivalent to the mean low flows of the spring $\left(\sim 1.3 \mathrm{~m}^{3} \mathrm{~s}^{-1}\right)$.

\section{CONCEPTUAL TANK MODELS}

As a first simplifying approach for modelling the WSCs in a karst, conceptual tanks model may be used (e.g. Tritz et al. 2011; Mazzilli et al. 2012; Deville et al. 2013). They can be interpreted later on as different karst compartments. Many tank model setups are possible with different numbers of reservoirs and different connections between them, depending on the system studied and the purpose researched. In classical tanks studies, the karst system is constrained by the spring discharge, and then can only be evaluated at the catchment scale. At the local scale, the lower boundary condition (groundwater flow out of the model) and WSC are in general unknown. With gravity data (and local rain and evaporation data) tanks models can be done at the local scale. One can note that such models were already performed on others sites in the Durzon catchment (Jacob et al. 2008; Deville et al. 2013) but with AG monthly FG5 measurements and never with continuous and precise SG time-series.

\subsection{Models setup}

The model of Deville et al. (2013) were used, composed of 2 tanks in series and governed by Maillet linear discharge law (eq. 3) depending on water height in the tanks:

$Q=\frac{1}{T_{\mathrm{c}}}\left(h-H_{\mathrm{t}}\right)$

Where $Q$ is the discharge, $T_{\mathrm{c}}$ the characteristic time of the discharge, $h$ the water height in the tank and $H_{\mathrm{t}}$ the threshold height (for the first tank only). Associated gravity variations were calculated from the water height in the two tanks with the Bouguer equation assuming infinite horizontal slabs (eq. 4). However the water heights in the tanks were scaled by coefficients as in Deville et al. (2013):

$g_{\mathrm{c}}=2 \pi \rho_{\mathrm{w}} G\left(h_{1} C_{1}+h_{2} C_{2}\right)$

Where $g_{\mathrm{c}}$ is the computed gravity, $\rho_{\mathrm{w}}$ the density of water, $G$ the universal gravitational constant, $h_{1}$ and $h_{2}$ the water heights in the first and second tank, and $C_{1}$ and $C_{2}$ the scaling coefficients of the two tanks. $C_{1}$ simulates the mask effect while the $C_{2}$ simulates potential lateral water fluxes.

From the direct analysis of the building effect depending on the water depth (Fig. 6), $C_{1}$ should range between 0.2 and 1. Small $C_{1}$, high $H_{\mathrm{t}}$ and $T_{\mathrm{c} 1}$ indicate important and long storage of water near the surface (the first meters). $C_{1}$ value close to 1 rather indicates fast infiltration up to a depth with an insignificant mask effect. $C_{2}$ value close to 1 indicates no significant lateral water fluxes and no fast transfer to the spring. The best parameters $C_{1}, C_{2}, T_{\mathrm{c} 1,} T_{\mathrm{c} 2}$, and $H_{\mathrm{t}}$ are searched with a pseudo Monte-Carlo algorithm (Sambridge 1999a). The warm-up stage of the model is $8 \mathrm{yr}$ before the beginning of the gravity data and the models run with daily steps. 
Table 2. Gravity effect of major rain events. Because of the building mask effect, different responses occur depending on the soil moisture. The admittance is the observed gravity increase divided by the theoretical infinite slab effect, in per cent.

\begin{tabular}{|c|c|c|c|c|}
\hline $\begin{array}{l}\text { Rainfall } \\
\text { event }\end{array}$ & $\begin{array}{c}\text { Rainfall } \\
\text { amount } \\
(\mathrm{mm}) / \\
\left(\mathrm{nm} \mathrm{s}^{-2}\right)\end{array}$ & $\begin{array}{c}\text { Rainfall } \\
\text { amount of the } \\
\text { last } 2 \text { weeks } \\
(\mathrm{mm})\end{array}$ & $\begin{array}{c}\text { Gravity } \\
\text { increase/ } \\
\text { admittance } \\
\left(\mathrm{nm} \mathrm{s}^{-2}\right) /(\%)\end{array}$ & $\begin{array}{c}\text { Gravity increase } \\
\text { after } 10 \mathrm{~d} / \\
\text { admittance } \\
\left(\mathrm{nm} \mathrm{s}^{-2}\right) /(\%)\end{array}$ \\
\hline 2011 October 23-28 & $115 / 48$ & 0 & $10 / 21$ & $10 / 21$ \\
\hline 2011 November 3-5 & $250 / 105$ & 115 & $61 / 58$ & $88 / 84$ \\
\hline 2012 April/May 28-1 & $95 / 40$ & 40 & $10 / 25$ & $17 / 43$ \\
\hline 2012 October 19-21 & $63 / 26$ & 10 & $7 / 27$ & $10 / 38$ \\
\hline 2012 October 26 & $82 / 34$ & 73 & $17 / 49$ & $31 / 90$ \\
\hline 2013 March 5-6 & $82 / 34$ & 0 & $13 / 36$ & $19 / 55$ \\
\hline 2013 May $15-19$ & $125 / 52$ & 40 & $16 / 31$ & $35 / 67$ \\
\hline 2014 September $16-17$ & $100 / 42$ & 20 & $18 / 42$ & $23 / 55$ \\
\hline 2014 November $28-30$ & $205 / 86$ & 80 & $67 / 78$ & $93 / 108$ \\
\hline
\end{tabular}
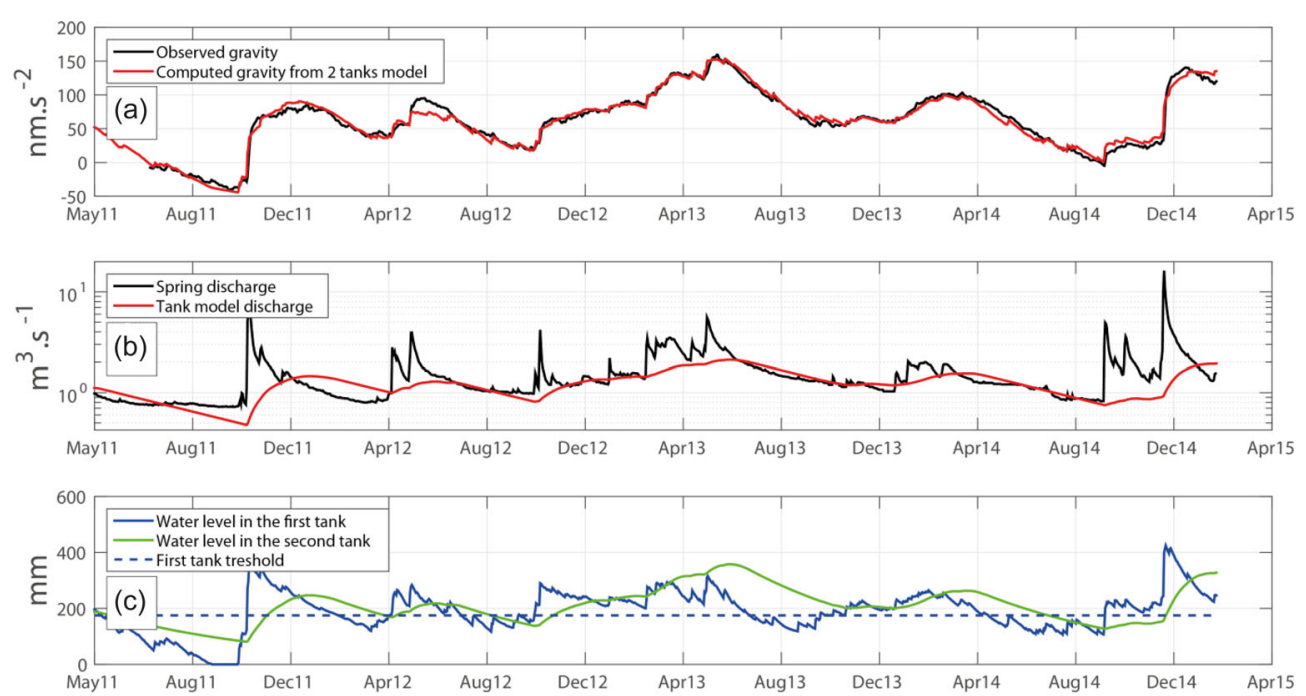

Figure 7. Results of the best two tanks model. (a) Observed gravity residuals (black), modelled gravity (red). (b) Logarithmic $y$-axis: observed spring discharge (black), modelled discharge scaled by the basin surface (red). (c) Water height in the first (blue) and second (green) tanks. The dotted blue line represents the threshold of the first tank.

\subsection{Models results}

Simulations were also done with one tank only (not shown). The best 1-tank simulation has a RMS of $\sim 13 \mathrm{~nm} \mathrm{~s}^{-2}$, slightly better than the simple water balance $\left(17 \mathrm{~nm} \mathrm{~s}^{-2}\right)$. The characteristic time is found high $(340 \mathrm{~d})$, leading to a quasi-constant output flow during the 3 yr of gravity measurements.

With 2 tanks, the RMS decreases by a factor 2 , around $6 \mathrm{~nm}$ $\mathrm{s}^{-2}$. The simulated gravity reproduces almost perfectly the observed gravity variations (Fig. 7a). Looking at the parameters of the 2-tanks model calibrated on the full gravity time-series (Table 3, first line), the characteristic time $35 \mathrm{~d}$ for the first tank. The optimal threshold height about $170 \mathrm{~mm}$ for the first tank which can be completely emptied by evapotranspiration during long drought like in late summer 2011 (Fig. 7c). The nonlinearity of the ratio between rain and gravity due to the mask effect and soil moisture is well modelled through the threshold of the first tank: the water flows into the second tank with a speed related to the pre-event water level in the first tank.

On the contrary, the second tank has a long specific characteristic time of $215 \mathrm{~d}$ (Table 3). During the 3 yr of gravity data, the discharge from the second tank varies slowly (from 0.8 to $1.2 \mathrm{~mm} \mathrm{~d}^{-1}$ ). Scaling the local discharge by the basin surface (Fig. 7b), one can remark the fit in amplitude but also in shape with the measured low flows of the Durzon spring, especially after the meteorological data update (October 2012). It supports the assumption made from the previous mass balance with a constant discharge, namely that WSC at the observatory scale are representative of the average low flows of the whole catchment.

The added-value after 2013 of AET from flux tower measurements and the new rain gauges is not the quality of the fit. The number of parameters is large enough to fit the observed gravity even with a poor accuracy on AET or precipitation. For example, the overestimation of the evapotranspiration is compensated during the 2011 drought by emptying the first tank (Fig. 7c). To evaluate the impact of the AET and precipitation accuracy, the time-series was split in two parts: before and after 2013. The models then ran separately on each part. The parameters found (Table 3 ) are quite similar for both periods, except for the first tank characteristic time, which is higher before 2013. Actually, a large first tank characteristic time tends to compensate AET and rain amounts error. By keeping water in the first tank for a long duration (the gravitational effect of which is reduced by 50 percent by the mask effect), the errors in evapotranspiration (underestimation during winter and overestimation during summer) are delayed and compensated by the next rains. One can also note that the high second tank characteristic time is better constrained using only 2013-2015, however the added value 
Table 3. Parameters of the 2-tanks hydrologic model shown in Fig. 7. $C_{1}$ and $C_{2}$ correspond to the scaling coefficients associated with the upper and the lower reservoirs, $T_{\mathrm{c} 1}$ and $T_{\mathrm{c} 2}$ are the characteristic transfer time for the upper and the lower reservoirs, and $H_{\mathrm{t} 1}$ is the threshold height of the upper reservoir. The errors are estimated by an ensemble inference algorithm (Sambridge 1999b), developed specifically for the pseudo Monte-Carlo algorithm used (Sambridge 1999a).

\begin{tabular}{lcccccc}
\hline Calibration period & RMS $\left(\mathrm{nm} \mathrm{s}^{-2}\right)$ & $H_{\mathrm{t} 1}(\mathrm{~mm})$ & $T_{\mathrm{c} 1}(\mathrm{~d})$ & $C_{1}$ & $T_{\mathrm{c} 2}(\mathrm{~d})$ & $C_{2}$ \\
\hline $2011-2015$ & 6.8 & $174 \pm 20$ & $35 \pm 12$ & $0.52 \pm 0.05$ & $215 \pm 80$ & $1.23 \pm 0.08$ \\
$2011-2013$ & 7.3 & $162 \pm 28$ & $38 \pm 4.5$ & $0.53 \pm 0.05$ & $348 \pm 60$ & $1.14 \pm 0.11$ \\
$2013-2015$ & 5.8 & $157 \pm 22$ & $16 \pm 4.8$ & $0.53 \pm 0.03$ & $293 \pm 35$ & $1.16 \pm 0.06$ \\
\hline
\end{tabular}

of accurate meteorological measurements is rather to allow convergence towards more realistic parameters than to reduce the misfit between observed and simulated gravity changes.

\section{DISCUSSION}

\subsection{Hydrogeological interpretation}

Considering that the parameters estimated with the SG dataset are well constrained, one can try to interpret the different tanks as karst reservoirs and the parameters as hydrological processes. The first tank could represent the soil (and a high weathered dolomite zone) whose thickness can be obtained from the estimated value of $C_{1}$ (0.53) and the expected magnitude of the masking effect: from Fig. 6, an admittance of 0.53 corresponds to the mean value from the surface to $4.5 \mathrm{~m}$ depth. We use here the parameters found on the period 2013-2015 (Table 3, last line) as this tank is connected to the surface and very sensitive to meteorological data. Then, the mean groundwater velocity through the soil can be estimated at $0.28 \mathrm{~m} \mathrm{~d}^{-1}$ from this depth $(4.5 \mathrm{~m})$ and the characteristic time of the first tank $\left(T \mathrm{c}_{1}, 16 \mathrm{~d}\right)$. Indeed, most of the rain water (two thirds of the amount above the threshold, eq. 3) is transferred into the second reservoir after this time. One can also obtain a minimum soil porosity of 9 per cent by dividing the maximum water height in the first tank (400 mm, Fig. 7c) by the soil thickness $(4.5 \mathrm{~m})$. This is in accordance with the porosity estimated from dolomite samples standing around 10 per cent (Jacob et al. 2009).

The building mask effect $\left(C_{1}\right)$ and the first reservoir threshold $\left(H_{\mathrm{t} 1}\right)$ allow the modelling of the nonlinearity between gravity and rainfall, taking into account the previous precipitations amount and the soil thickness. When the pre-event soil moisture content is high (significantly above the threshold as in November 2011 and November 2014), the incoming water acts as a piston and increases water storage at greater depth with a reduced mask effect. Such a piston effect is one source of nonlinearity of the karstic flow and is clearly seen on the whole Durzon hydrosystem from chemical analysis (Pinault et al. 2001).

As in Jacob et al. (2008), we associate the second tank with the epikarst reservoir. The Durzon catchment epikarst is known to be a significant reservoir with long residence time which indicates preferential water storage in the dolomite matrix porosity. In previous geological and geophysical studies (Ricard \& Bakalowicz 1996; Jacob et al. 2009; Deville et al. 2013), high transfer times are found in the south of the catchment and close to temporary lakes. The parameters obtained at the GEK site are comparable to those estimated by Deville et al. (2013) especially for the southern AG site (SALV) whereas the observatory is in the northern part close to the Durzon spring.

The fit between observed and computed gravity in all the models (mass balance and tanks) strongly supports the assumption of a homogeneous epikarst at the gravimeter scale as water storage heterogeneities would change the relation with gravity (eq. 1). The local WSC at the observatory scale is representative of the average low flow discharge at the basin scale. The Durzon low flow in summer is probably only supported by the slow discharge from the epikarst. Fast water transfer could occur on specific geomorphological units such as sinkholes or trough piston-type fast flow as hypothesized by Ricard \& Bakalowicz (1996) from hydrochemistry observations.

However, it states water budget incoherence: scaling by a basin surface of $110 \mathrm{~km}^{2}$, the modelled flow reaches only 85 per cent of the total measured spring discharge over the $3 \mathrm{yr}$. To close the water budget at the basin scale, three hypotheses can be proposed: (1) additional runoff which is unlikely as no significant runoff is observed on the whole Durzon area. (2) The mean annual rainfall and evapotranspiration measured at the observatory are not representative of the mean precipitation of the whole Durzon basin. (3) The estimated area of the Durzon basin is larger (at least during high precipitation event) than the $110 \mathrm{~km}^{2}$ found in previous studies (Tritz et al. 2011; Mazzilli et al. 2012). An extension of Durzon area of $20 \mathrm{~km}^{2}$ up to $130 \mathrm{~km}^{2}$ is sufficient to close the water mass balance.

\subsection{Advantages of SG continuous time-series}

The added value of a continuous SG sampling was also evaluated and compared to a synthetic AG dataset. The existing AG measurements (used for drift and calibration, Fig. 3) were completed by few virtual data (SG gravity values with a random noise up to $\pm 20 \mathrm{~nm} \mathrm{~s}^{-2}$ ) where there were gaps. One can note that such a real and dense AG dataset is time consuming and dependent of the availability of the few existing AGs.

One surprising result (in a karstic system) is the complete absence of fast transfer. We have investigated models with possibility of fast transfer by adding a fast circuit in parallel of the second tank, as in Fleury et al. (2007). The partitioning coefficient $X$ used to share the output of the first tank was searched between 0 (all the water goes in the slow tank) and 1 (all in the fast circuit). On the simulated absolute gravity observations, mass losses due to fast transfer can be artificially and completely compensated by increasing the scaling coefficient $C_{2}$. Then $\mathrm{C}_{2}$ was limited to 1 in order to prevent trade-off between $C_{2}$ and $X$. This choice was motivated by the fact that no lateral transfer is expected and no others reasonable hypotheses can explain an overshoot of the Bouguer effect $\left(C_{2}>1\right.$, eq. 4$)$.

Despite the precaution to constrain $C_{2}$ to 1 , the lack of continuity and precision of AG data allows fast transfer up to 15 per cent of the rainfall amounts without any RMS degradation $\left(15 \mathrm{~nm} \mathrm{~s}^{-2}\right.$, Fig. 8a). As stated by Jacob et al. (2010), monthly AG dataset cannot discriminate between different tank models configurations. On the contrary simulated gravity from models with significant fast direct transfer to the spring never fits the SG time-series. One can note that 15 per cent is also the estimated part of fast transfer on the whole basin (Pinault et al. 2001). Then it reproduces better the flood peaks while being less representative of the base-flow (red line, Fig. 8b). Quantification of fast groundwater transfer is necessary for groundwater resources 

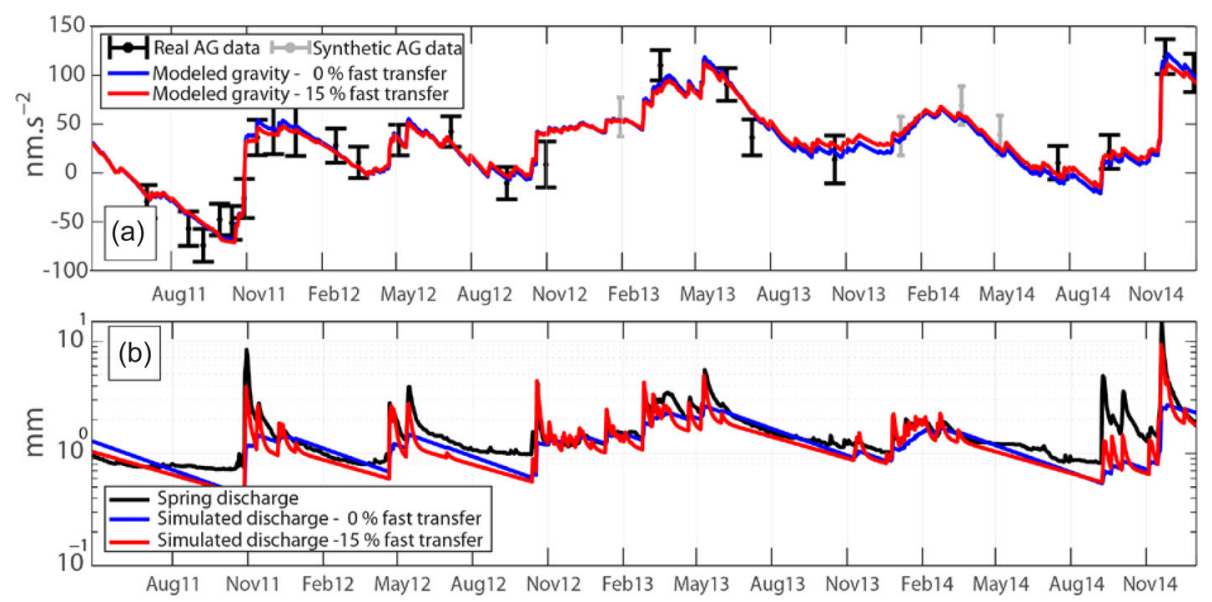

Figure 8. Results of tanks model calibrated by AG data set. (a) FG5 measurement (black point) and synthetic AG measurement (grey point) with error bars (set to $\pm 20 \mathrm{~nm} \mathrm{~s}^{-2}$ for synthetic data). The blue line represents the gravity computed from the model without fast transfer. The red line represents the gravity computed from a model where 15 per cent of the first tank discharge goes directly to the spring. (b) Scaled (by $110 \mathrm{~km}^{2}$ ) discharge of the models with (red line) and without (blue line) the 15 per cent of fast transfer. The Durzon spring discharge is represented by the black line.

vulnerability studies yet with only AG data available the choice of the modelled processes is arbitrary. SG precise and continuous data, along with local rainfall and precise actual ET, allows quantifying each type of transfer (fast and slow). Therefore, benefits of the continuous dataset are more fundamental than only the reduction in parameter uncertainty and dynamics in the first meters beneath the surface.

Previous studies on the Durzon catchment from AG dataset (Jacob et al. 2008 and Deville et al. 2013) focus only on slow transfer models because of that impossibility to discriminate one model among others with AG data only. However time-laps microgravity maps (Jacob et al. 2010) show heterogeneous storage on the basin. With the SG, we confirm the high storage expected around the GEK. It would be interesting to move the iGrav where smaller storage is expected from the time-laps microgravity maps to investigate the fast transfers.

\section{PERSPECTIVE OF ASSIMILATION IN PHYSICAL MODELS}

Examples on the use of gravity data for physical models calibration are few (especially in the unsaturated zone) and the impact on parameters estimation is not demonstrated in all cases. Most of the studies including gravity measurements (including synthetic gravity dataset) have been done during pumping test (Damiata \& Lee 2006; Blainey et al. 2007; Herckenrath et al. 2012) or focusing on the saturated zone (Piccolroaz et al. 2015).

Calibration of physical models with gravity data in karstic hydrosystems is challenging as fast and slow flows are generally present. The previous conceptual models have demonstrated that the epikarst surrounding the observatory, albeit heterogeneous at the local borehole scale, is seen homogeneous for a gravimeter. The epikarst hydrology at the observatory scale $(\sim 100 \mathrm{~m})$ appears to be a slow and uniform vertical flow, and a quasi-constant deep output. Therefore the system can be considered, at least at the gravity scale, as a classic porous media and physical models based on the Richards equation for flows in unsaturated media (Richards 1931) may apply.

To constrain physical models, complementary and depthdependent observables will be needed as gravity lacks of depth resolution. Water table depth variations from boreholes when available (perched aquifers or base level) could be used. But they are representatives of an unknown scale and of different processes (lateral fluxes in saturated aquifers). Ambient seismic noise monitoring, sensitive to water saturation and frequency depth-dependent, is currently tested as it is complementary to the water content gravity information while having a large investigating scale. Time lapse electrical resistivity tomography is another potential complementary depth sensitive observation.

\section{CONCLUSIONS}

In the study, 3 yr of continuous gravity data from a SG were used to characterize the precision and the stability of the GWR iGrav a new generation of gravimeter. Noise level and a small $45 \mathrm{~nm} \mathrm{~s}^{-2} \mathrm{yr}^{-1}$ drift were carefully determined. The SG and the observatory site provide well suited measurements for hydrological investigations at various time scales. The interpretation of the SG residuals with the help of accurate meteorological measurements (local precipitation and actual evapotranspiration from a flux tower) has clearly demonstrated hydrological induced gravity variations. The GEK observatory is located in a complex karstic system in a Mediterranean climate where water quantity and quality management is a challenge. Local gravity-data driven simulation of the mass balance taking into account the site effects allowed quantifying water transfer types and storage in the soil and in the epikarst. The dolomites around the observatory were found homogeneous with insignificant fast transfer to the spring even during high precipitation events. Such an unambiguous characterization of the type of transfer was not possible from AG data only. Consequently, assimilation of the iGrav time-series in 1-D physical model is possible. Gravity alone cannot constrain the model and complementary observations at the same scale of investigations are needed. To spatially extend the conclusions obtained at the observatory, the iGrav should be moved away from the GEK in a field enclosure. Because the area appeared to be representative only of the slow transfer of the basin, the iGrav could be settled in the near future in an area where fast transfer is expected. 


\section{ACK NOWLEDGEMENTS}

This work was funded by the OSU OREME (Observatoire des Sciences de l'Univers - Observatoire de REcherche Méditerranéen de l'Environnement), the H+ National Observation System (SNO) and the HydroKarst $G^{2}$ project of the French Agence Nationale de la Recherche (ANR). The CNRS-INSU (Centre National de la Recherche Scientifique - Institut National des Sciences de l'Univers) and the Languedoc-Roussillon region have provided significant financial support for the acquisition of the GWR iGrav superconducting gravimeter. The FG5 gravity measurements were performed thanks to CNRS-INSU national facility RESIF-GMOB (REseau SIsmologique et géodésique Français - parc de Gravimétres MOBiles). We would like to thank all the people who helped in the installation of the GEK observatory, especially P. Vernant, P. Collard, E. Doerflinger and M. Bonno. We also would like to express our gratitude towards F. Grosbeau, J. Fabre and O. Lobry for the data transfer. Finally, we would like to acknowledge J.-P. Boy for computing the global hydrological effects, and the Hospitalet-duLarzac municipality for its help. All the measurements from the observatory are freely available through the online database of the SNO H+ and the OSU OREME: http://data.oreme.org/gek/home and http://hplus.ore.fr.

\section{REFERENCES}

Allan, D.W., 1987. Time and frequency(time-domain) characterization, estimation, and prediction of precision clocks and oscillators, IEEE Trans. Ultrason. Ferroelectr. Freq. Control, 34(6), 647-654.

Banka, D., 1997. Noise levels of superconducting gravimeters at seismic frequencies, $P h D$ thesis, GDMB-Information-gesellschaft mbH, Clausthal., Germany.

Blainey, J.B., Ferré, T. \& Cordova, J.T., 2007. Assessing the likely value of gravity and drawdown measurements to constrain estimates of hydraulic conductivity and specific yield during unconfined aquifer testing, Water Resour. Res., 43(12), doi:10.1029/2006WR005678.

Bruxelles, L., 2001. Dépôts et altérites des plateaux du Larzac central: causses de l'Hospitalet et de Campestre (Aveyron, Gard, Hérault). Evolution Morphogénique, Conséquences Géologiques et Implications Pour l'aménagement, PhD thesis, Université de Provence, Aix-en-Provence.

Chalikakis, K., Plagnes, V., Guerin, R., Valois, R. \& Bosch, F.P., 2011. Contribution of geophysical methods to karst-system exploration: an overview, Hydrogeol. J., 19(6), 1169-1180.

Creutzfeldt, B., Güntner, A., Vorogushyn, S. \& Merz, B., 2010a. The benefits of gravimeter observations for modelling water storage changes at the field scale, Hydrol. Earth Syst. Sci., 14(9), 1715-1730.

Creutzfeldt, B., Güntner, A., Wziontek, H. \& Merz, B., 2010b. Reducing local hydrology from high-precision gravity measurements: a lysimeterbased approach, Geophys. J. Int., 183(1), 178-187.

Damiata, B.N. \& Lee, T.C., 2006. Simulated gravitational response to hydraulic testing of unconfined aquifers, J. Hydrol., 318(1), 348359.

Deville, S., Champollion, C., Doerflinger, E., Le Moigne, N., Bayer, R. \& Vernant, P., 2011. Studying unsaturated epikarst water storage properties by time lapse surface to depth gravity measurements, in AGU Fall Meeting Abstracts, Vol. 1, 07 pp.

Deville, S., Jacob, T., Chery, J. \& Champollion, C., 2013. On the impact of topography and building mask on time varying gravity due to local hydrology, Geophys. J. Int., 192, 82-93.

Dubois, C. et al., 2014. The process of ghost-rock karstification and its role in the formation of cave systems, Earth-Sci. Rev., 131, 116-148.

Fleury, P., Plagnes, V. \& Bakalowicz, M., 2007. Modelling of the functioning of karst aquifers with a reservoir model: application to Fontaine de Vaucluse (South of France), J. Hydrol., 345(1), 38-49.
Ford, D. \& Williams, P.D., 2013. Karst Hydrogeology and Geomorphology, John Wiley \& Sons.

Francis, O., 1997. Calibration of the C021 superconducting gravimeter in Membach (Belgium) using 47 days of absolute gravity measurements, in Gravity, Geoid and Marine Geodesy, pp. 212-219, eds Segawa, J., Fujimoto, H. \& Okubo, S., Springer.

Francis, O., Niebauer, T.M., Sasagawa, G., Klopping, F. \& Gschwind, J., 1998. Calibration of a superconducting gravimeter by comparison with an absolute gravimeter FG5 in Boulder, Geophys. Res. Lett., 25(7), 10751078.

Hasan, S., Troch, P.A., Bogaart, P.W. \& Kroner, C., 2008. Evaluating catchment-scale hydrological modeling by means of terrestrial gravity observations, Water Resour. Res., 44(8), doi:10.1029/2007WR006321.

Hector, B., Séguis, L., Hinderer, J., Descloitres, M., Vouillamoz, J.M., Wubda, M. \& Le Moigne, N., 2013. Gravity effect of water storage changes in a weathered hard-rock aquifer in West Africa: results from joint absolute gravity, hydrological monitoring and geophysical prospection, Geophys. J. Int., 194(2), 737-750.

Hector, B. et al., 2014. Hydro-gravimetry in West-Africa: first results from the Djougou (Benin) superconducting gravimeter, J. Geodyn., 80, 34-49.

Herckenrath, D., Auken, E., Christiansen, L., Behroozmand, A.A. \& BauerGottwein, P., 2012. Coupled hydrogeophysical inversion using time-lapse magnetic resonance sounding and time-lapse gravity data for hydraulic aquifer testing: will it work in practice?, Water Resour. Res., 48(1), doi:10.1029/2011WR010411.

Hinderer, J., Florsch, N., Mäkinen, J., Legros, H. \& Faller, J.E., 1991. On the calibration of a superconducting gravimeter using absolute gravity measurements, Geophys. J. Int., 106(2), 491-497.

Hinderer, J. \& Crossley, D., 2004. Scientific achievements from the first phase (1997-2003) of the Global Geodynamics Project using a worldwide network of superconducting gravimeters, J. Geodyn., 38(3), 237-262.

Hinderer, J., Amalvict, M., Florsch, N., Francis, O. \& Mäkinen, J., 1998. On the calibration of superconducting gravimeters with the help of absolute gravity measurements, in Thirteenth International Symposium on the Earth Tides, Brussels, pp. 557-564.

Hinderer, J., Crossley, D. \& Warburton, R.J., 2007. Gravimetric methodssuperconducting gravity meters, Treatise Geophys., 3, 65-122.

Jacob, T., Bayer, R., Chery, J., Jourde, H., Le Moigne, N., Boy, J.P. \& Brunet, P., 2008. Absolute gravity monitoring of water storage variation in a karst aquifer on the larzac plateau (Southern France), J. Hydrol., 359(1), 105-117.

Jacob, T., Chery, J., Bayer, R., Le Moigne, N., Boy, J.P., Vernant, P. \& Boudin, F., 2009. Time-lapse surface to depth gravity measurements on a karst system reveal the dominant role of the epikarst as a water storage entity, Geophys. J. Int., 177(2), 347-360.

Jacob, T., Bayer, R., Chery, J. \& Le Moigne, N., 2010. Time-lapse microgravity surveys reveal water storage heterogeneity of a karst aquifer, $J$. geophys. Res., 115(B6), doi:10.1029/2009JB006616.

Kennedy, J., Ferré, T., Güntner, A., Abe, M. \& Creutzfeldt, B., 2014. Direct measurement of subsurface mass change using the variable baseline gravity gradient method, Geophys. Res. Lett., 41(8), 2827-2834.

Kudryavtsev, S.M., 2004. Improved harmonic development of the Earth tide-generating potential, J. Geod., 77(12), 829-838.

Le Moigne, N. et al., 2011. New iGrav superconducting gravimeter: accuracy, drift and first results, in AGU Fall Meeting Abstracts, Vol. 1, 0955 pp.

Longuevergne, L. et al., 2009. Local and global hydrological contributions to gravity variations observed in Strasbourg, J. Geodyn., 48(3), 189-194.

Mazzilli, N., Guinot, V. \& Jourde, H., 2012. Sensitivity analysis of conceptual model calibration to initialisation bias. Application to karst spring discharge models, Adv. Water Resour., 42, 1-16.

McCulloh, T.H., 1965. A confirmation by gravity measurements of an underground density profile based on core densities, Geophysics, 30(6), $1108-1132$.

Niebauer, T.M., Sasagawa, G.S., Faller, J.E., Hilt, R. \& Klopping, F., 1995. A new generation of absolute gravimeters, Metrologia, 32(3), 159.

Penman, H.L., 1948. April. Natural evaporation from open water, bare soil and grass, Proc. R. Soc. A, 193(1032), 120-145. 
Pfeffer, J. et al., 2013. Evaluating surface and subsurface water storage variations at small time and space scales from relative gravity measurements in semiarid Niger, Water Resour. Res., 49(6), 32763291.

Piccolroaz, S., Majone, B., Palmieri, F., Cassiani, G. \& Bellin, A., 2015. On the use of spatially distributed, time-lapse microgravity surveys to inform hydrological modeling, Water Resour. Res., 51, 72707288.

Pinault, J.L., Plagnes, V., Aquilina, L. \& Bakalowicz, M., 2001. Inverse modeling of the hydrological and the hydrochemical behavior of hydrosystems: characterization of karst system functioning, Water Resour. Res., 37(8), 2191-2204.

Ricard, J. \& Bakalowicz, M., 1996. Connaissance, aménagement et protection des ressources en eau du Larzac septentrional. Aveyron (France). Report R38953, BRGM, Orléans.

Richards, L.A., 1931. Capillary conduction of liquids through porous mediums, J. Appl. Phys., 1(5), 318-333.

Sambridge, M., 1999a. Geophysical inversion with a neighbourhood algorithm-I. Searching a parameter space, Geophys. J. Int., 138(2), 479494.

Sambridge, M., 1999b. Geophysical inversion with a neighbourhood algorithm-II. Appraising the ensemble, Geophys. J. Int., 138(3), 727746.

Tritz, S., Guinot, V. \& Jourde, H., 2011. Modelling the behaviour of a karst system catchment using non-linear hysteretic conceptual model, $J$. Hydrol., 397(3), 250-262.

Van Camp, M. \& Francis, O., 2007. Is the instrumental drift of superconducting gravimeters a linear or exponential function of time?, J. Geod., 81(5), 337-344.

Warburton, R.J., Pillai, H. \& Reineman, R.C., 2010. Initial results with the new GWR iGrav ${ }^{\mathrm{TM}}$ superconducting gravity meter, in Extended Abstract Presented at 2nd Asia Workshop on Superconducting Gravimetry, Taipei, Taiwan.

Wenzel, H.G., 1996. The nanogal software: Earth tide data processing package ETERNA 3.30, Bull. Inf. Marées Terrestres, 124, 9425-9439.

\section{SUPPORTING INFORMATION}

Additional Supporting Information may be found in the online version of this paper:

Figure S1. Components of the gravity signal on the year 2012 (left) and zoomed on the week 43 (right). (a) Tides model (ocean and solid) from the ETERNA software (Wenzel 1996) and SG data analysis. (b) Pressure local (blue) and non-local (red) effects. (c) Hydrological local (blue) and non-local (red) effects. (d) Polar motion contribution.

Figure S2. Mean PSD of five quiet days expressed in $\mathrm{dB}$ relative to $1 \mathrm{~m}^{2} \mathrm{~s}^{-4} \mathrm{~Hz}^{-1}$. New (High and Low) Noise Model (NHNM and NLNM) in red is the envelope of noise found on vertical sensors at GSN (Global Seismographic Network) stations (Peterson 1993 in the Supporting Information).

Figure S3. SNM on the 200-600 s period (circles) for the GGP network SGs and two STS-1 seismometers (Echery and BFO). SNM is also computed on the 200-340 s period (squares) to show the impact of the decimation filter. SNM are computed on the 5 quietest days of the year 1998. For the iGrav \#OO2 (Larz), running since 2011, the SNM is computed on the 5 quietest days of the year 2014. For the iGrav \#002, SNM is computed on $1 \mathrm{~Hz}$ data, which explains why there are no differences between the two periods. Modified from Rosat et al. (2004) in the Supporting Information. (http://gji.oxfordjournals.org/lookup/suppl/doi:10.1093/gji/ ggw396/-/DC1)

Please note: Oxford University Press is not responsible for the content or functionality of any supporting materials supplied by the authors. Any queries (other than missing material) should be directed to the corresponding author for the paper. 